\title{
Effect of sward height and vertical distribution of clover on performance of cashmere goats in autumn
}

\author{
M. DEL POZO AND K. OSORO \\ Centro de Investigación Aplicada y Tecnología \\ Agroalimentaria, Villaviciosa, Asturias, Spain
}

\section{Abstract}

To investigate the effect of sward height on liveweight change in goats grazing grass/white clover swards, an experiment was conducted from mid-August to mid-November with groups of nonlactating female cashmere goats that continuously grazed perennial ryegrass (Lolium perenne)/white clover (Trifolium repens) swards. Three replicated different sward height treatments $-10-8 \mathrm{~cm}$ (high), $7-5 \mathrm{~cm}$ (medium) and $5-3 \mathrm{~cm}$ (low) - were used to examine the effects on the competitive ability of grass and clover components within the sward canopy and their effect on liveweight. The pasture after grazing by goats had relatively higher ryegrass leaf $(+0.26$, high; +0.32 , medium; and $+0 \cdot 18$, low) and lower dead ryegrass proportions $(-0.28$, high; -0.23 , medium; and $-0 \cdot 18$, low) than at the beginning of the experiment, whereas the white clover fraction in the sward remained constant $(+0.04$, high; -0.02 , medium; and +0.03 , low). Higher proportions of the white clover leaf lamina and petiole were found near the top of the sward canopy and were negatively correlated with the rate of liveweight gain by goats $(P<0.05)$. Goats gained $50.2 \mathrm{~g}$ Live weight (LW) $d^{-1}$ on the tallest treatment (high) but lost 0.01 and $42.3 \mathrm{~g} \mathrm{LW} \mathrm{d}^{-1}$ on the medium and low sward height treatments respectively (s.e.d. 13.21, $P<0.001)$. Liveweight changes that occurred between sampling periods were also correlated $\left(R^{2}=0.858, P<0.001\right)$ with changes in the mean sward height and proportion of white clover lamina-petiole at the sward surface in relation to the proportion found within the whole sward. These

Correspondence: Dr M. del Pozo Ramos, CIATA, Apdo 13, 33300 Villaviciosa, Asturias, Spain. results suggest that goat liveweight gains would be increased if another species was introduced to reduce the white clover proportion in the surface horizon.

\section{Introduction}

A revival of interest in Europe in low-input grazing systems has recently favoured the introduction of fibre-producing goats to different pastoral resources of northern Spain (Osoro and Martinez, 1995) as an option in managing sward composition and diversifying animal production. However, the management of cashmere-producing goats to achieve acceptabie levels of production on grass/clover swards is constrained by the much greater herbage allowances needed to meet the requirements of goats than sheep (Merchant and Riach, 1994). The seasonal breeding calendar for farmed cashmere goats after kidding in early spring is for the does to be mated at the beginning of autumn. Consequently, a negative energy balance in autumn could affect the future growth rate and reproductive efficiency of these goats. This therefore suggests that for goats sward heights are kept tall after the summer drought to improve their performance, athough this may also bring deleterious effects on the amount of dead matter in the sward.

Under some circumstances sward characteristics may, however, override the influences exerted by height. Demment and Laca (1993) have argued that herbage mass itself does not affect animal performance as much as the spatial arrangement of its components. In addition, Milne et al. (1982) showed that sheep respond to sward conditions in the grazed stratum rather than to average conditions in the whole sward. Although research performed by Clark et al. (1984), McGregor (1985) and Lambert et al. (1987) reported increases in the white clover content in grass/white clover pastures grazed by goats or sheep and goats, other experiments (Radcliffe and Francis, 1988; Townsend and Radcliffe, 1990; del Pozo and

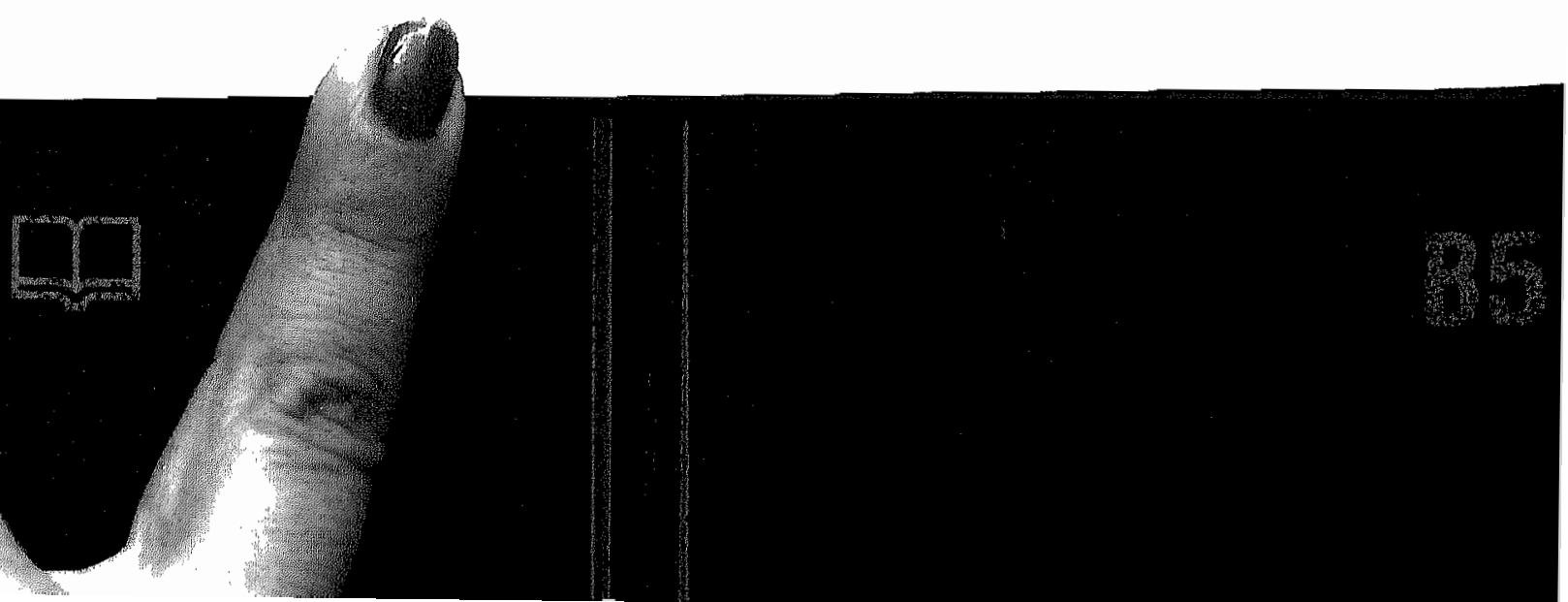


Wright, 1995) have examined the effect of increased clover on the performance of sheep but with little attention to that of goats. In particulat, the possibility that goat performance could not only be influenced by the amount of leafy material or the proportions of live grass and clover in the swards but also by their distribution within the pasture has not yet been fully assessed. Several authors, such as Hughes et al. (1984), Nicol and Collins (1990) and Stevens et al. (1992b; 1993), have shown increases in goat performance as the legume content of the sward increases, but these could be of limited value in different environmental conditions.

Furthermore, a restricted white clover growing season implies that the clover enhancement in the sward by goat grazing could disappear with the onset of the autumn rains and decreased temperatures (Barthram et al., 1992). Therefore, the vertical and horizontal distribution of clover and grass in the sward could differ during the grazing cycle and with different sward management criteria. When cashmere goats are used also for meat production (Glimp, 1995), the importance of these physical sward arrangements on liveweight performance needs to be examined. The aim of this experiment was to examine the effect of sward height and clover content on liveweight change of cashmere goats grazing ryegrass/white clover swards from mid-summer to mid-autumn, so that appropriate guidelines for the use of fibre-producing goats may be determined.

\section{Material and methods \\ Experimental management}

The experiment was conducted at La Mata Research Farm (Grado) located at $50 \mathrm{~m}$ a.s.1., Asturias, northern Spain, in 1995. The sward was sown in November 1991 with a mixture of $20 \mathrm{~kg} \mathrm{ha}^{-1}$ perennial ryegrass (Lolium perenne L. cv. Phoenix) plus $3 \mathrm{~kg} \mathrm{ha} \mathrm{a}^{-1}$ white clover (Trifolium repens L. cv. Huia) and received an application of $40 \mathrm{~kg} \mathrm{ha}^{-1} \mathrm{~N}$, $100 \mathrm{~kg} \mathrm{ha}^{-1} \mathrm{P}_{2} \mathrm{O}_{5}$ and $80 \mathrm{~kg} \mathrm{ha}^{-1} \mathrm{~K}_{2} \mathrm{O}$ on 25 January 1995. Before the experiment started, the experimental area was grazed to a mean height of $8 \mathrm{~cm}$ by ewes and does, and their offspring, to prevent seedhead development in summer.

After all stock were removed, six paddocks of 0.7 ha were established and continuously grazed from 17 August to 14 November with groups of dry does from a herd of 73 cashmere goats of mixed age $[29.2 \pm 0.29 \mathrm{~kg}$ live weight (LW) $]$. The experimental groups were stratified for genotype and age, and allocated randomly to six paddocks in which mean sward heights were initially 10 (high), 7 (medium) and $5 \mathrm{~cm}$ (low) and then grazed until paddocks had sward heights of 8,5 and $3 \mathrm{~cm}$, respectively, at the end of the experiment. Each treatment was replicated. Each group grazed on the same paddock continuously throughout the experimental period and was run together with a single buck for mating purposes. The goats were regularly drenched with Netobimin (20 mg kg-1 LW) to control gastrointestinal parasites.

\section{Measurentents}

Meteorological data. Daily air temperature and total rainfall were recorded at the experimental site.

Pasture. Pasture surface height $(\mathrm{cm})$, defined as the unextended height of grass and white clover leaf, was estimated weekly with an HFRO sward stick (Barthram, 1986) taking forty readings at random in each paddock. Frequency and distributions of sward heights were fitted for each treatment according to Gibb and Ridout $(1986 ; 1988)$ to estimate the proportion of the shorter ('frequently') and the taller ('infrequently') grazed populations.

The relative abundance of the different herbage components within the sward canopy was recorded in each paddock at the beginning ( 17 August, d0), at the end of the experiment (14 November, d89), and whenever experimental animals were weighed ( 19 September, $d 33$ and 10 October, d54), by using an inclined $\left(32.5^{\circ}\right)$ point quadrat apparatus (Grant, 1993) at twenty-five randomly selected points. As the point quadrat needle passed through the sward, each herbage contact height was noted after ground zero correction and classified using the following morphological units: perennial ryegrass (leaf, pseudostem, flower-stem or dead), white clover (lamina, petiole, stolon, flower or dead), other species and herbaceous weeds. In addition, 100 100-point estimates were made randomly across each paddock on a 'first hit' basis to describe sward surface composition.

Following Barthram and Grant (1994), the ratio of the total grass leaf, grass stem (pseudostem plus flower-stem), clover lamina-petiole or dead matter proportions on the sward surface, divided by their respective proportions in the whole sward, were calculated at each sampling period to examine the relative changes in their vertical distribution.

Animals. Liveweight changes were monitored by weighing individual animals on the same day as 
sward composition was determined. Simultaneously, body condition was measured by the same operator according to a scoring scale from 0 to 5 used for goats by Russel (1990).

\section{Statistical analysis}

All analysis of variance and regression analyses were conducted using Genstat 5.2 (Lawes Agricultural Trust, 1990), stating in each measurement period their corresponding standard errors of difference of means (s.e.d.). Paddock was treated as a blocking factor and sward height was considered as the treatment factor. Effects of age, initial live weight and body condition score of goats were used as covariates but did not show any significant effects. When vegetation data were analysed, frequency of herbage contacts were transformed by $\log _{10}+1$ before analysis but only back-transformed values, expressed as proportions, are included in the text. A Pearson's chi-square rest $\left(\chi^{2}\right)$ was used to describe the pattern of height distribution across treatments by comparing the proportion of measurements falling above $2 \mathrm{~cm}$ of the mean sward height.

Multiple linear regressions were calculated by stepwise regression to produce the simplest model that accounted for as much as possible of the significant variation in liveweight changes that occurred in goats between sampling dates. Mean sward surface height and sward changes in proportions and in ratios of white clover lamina-petiole, ryegrass leaf, ryegrass stem and dead matter were considered as potential explanatory variables.

\section{Results}

Weather

The mean annual precipitation was $976.9 \mathrm{~mm}$ (57 $\mathrm{mm}$ below a 25 -year average) and was greatest during the experiment in the $\mathrm{d} 33-\mathrm{d} 54$ interval $(105.3 \mathrm{~mm})$, with $22.4^{\circ} \mathrm{C}$ and $11.7^{\circ} \mathrm{C}$ being the mean maximum and minimum temperatures. However, the mean amount of rainfall for the $\mathrm{d} 0-\mathrm{d} 33$ and d54-d89 intervals (16.4 and $51.7 \mathrm{~mm}$ respectively) provided periods with below-average rainfall accompanied with above-average mean maximum $\left(24.2^{\circ} \mathrm{C}\right.$ and $19.9^{\circ} \mathrm{C}$ respectively) and minimum $\left(15.2^{\circ} \mathrm{C}\right.$ and $8.3^{\circ} \mathrm{C}$ respectiveiy) temperatures.

\section{Pasture composition}

Mean sward surface heights across treatments were
Table 1. Mean sward surface height (con) between simpling periods and the proportion of sward lecight measurenents fatling above $2 \mathrm{~cm}$ of the mean heigit acloss the different treatments

\begin{tabular}{lcccc}
\hline & \multicolumn{3}{c}{ Sward height treatment } & \\
\cline { 2 - 5 } Interval & $10-8 \mathrm{~cm}$ & $7-5 \mathrm{~cm}$ & $5-3 \mathrm{~cm}$ & s.e.d. \\
\hline $\mathrm{d} 0-\mathrm{d} 333(n=5)$ & 9.6 & 6.8 & 4.8 & 0.411 \\
$\mathrm{~d} 33-\mathrm{d} 54(n=3)$ & 8.5 & 6.2 & 4.1 & 0.572 \\
$\mathrm{~d} 54-\mathrm{d} 89(n=6)$ & 8.2 & 5.5 & 4.0 & 0.395 \\
Sward height & 0.08 & 0.06 & 0.0 .3 & 0.011 \\
$\quad$ proportion $(n=560)$ & & & & \\
\hline
\end{tabular}

successfully maintained within the range of target heights over the whole grazing season (Table 1). The target sward surface heiglits were reduced steadily from $10.1,7.2$ and $5.1 \mathrm{~cm}$ height (s.e.d. 0.301 ) at the beginning (d0) to $7.9,5.1$ and $3.0 \mathrm{~cm}$ height (s.e.d. 0.321 ) at the end of the experiment (d89) in the high, medium and low height treatments respectively.

The distribution of sward surface heights between treatments (Table 1) indicated that paddocks grazed at higher sward heights (high height treatment) did not have a more significantly skewed distribution than paddocks grazed at lower heights (medium and low height treatments) over the whole experimental period $\left(\chi^{2}=3.21\right.$; d.f. $\left.=2\right)$. No double normal distribution of sward heights was found across treatments.

Figure 1 illustrates the sward profiles of the different height treatments determined across the whole sward at each sampling period. These were obtained by plotting for ryegrass (leaf, stem and dead) and white clover (lamina-petiole and dead) components their point-quadrat contacts per 100 loci in each $1 \mathrm{~cm}$ horizon of the sward within the twenty-five points measured per paddock (see Forbes, 1982). Table 2 shows the composition of the clover lamina-petiole component present in the whole sward and at the sward surface and their ratios at each sampling period.

At the start of the experiment, there were no significant differences across sward height treatments in the proportions of the botanical components in the whole sward and in the sward surface respectively: ryegrass leaf $[0.23$, high; 0.24 , medium; and 0.31 , low (s.e.d. 0.049) and 0.57, high, 0.55; medium and $0 \cdot 60$, low (s.e.d. $0 \cdot 065$ )]; dead ryegrass $[0 \cdot 33$, high; 0.30 , medium; and 0.31 , low (s.e.d. 0.034 ) and $(0.13$, high; 0.12 , medium; 0.15 , low (s.e.d. 0.022)]; live clover $[0.16$, high; 0.18 , medium; 0.14 , low (s.e.d. 0.010 ) and 0.17 , high; 0.20 , medium; and

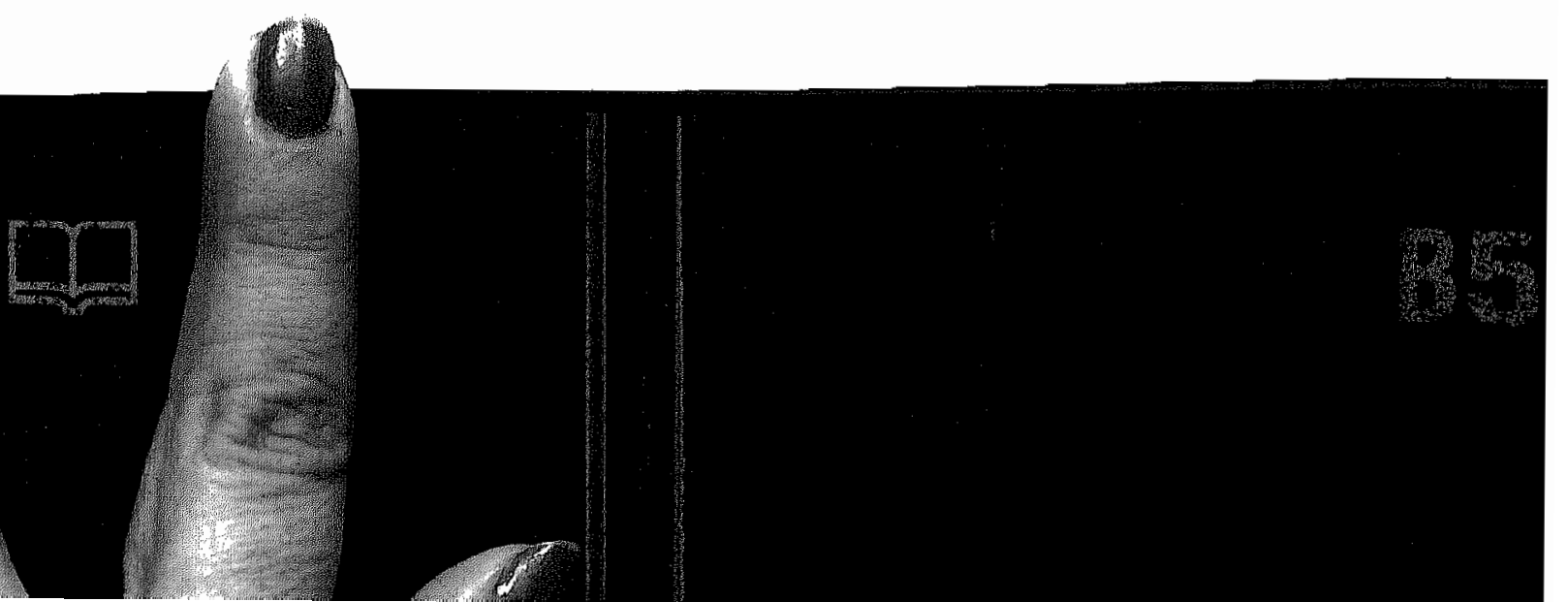




\section{August (d 0)}

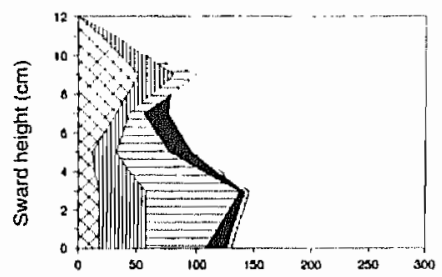

19 September (d 33)

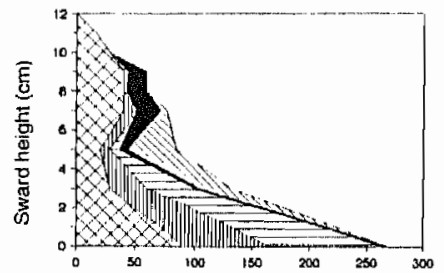

10 October (a 54)

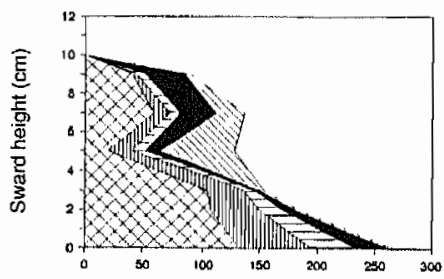

14 November (d 89)

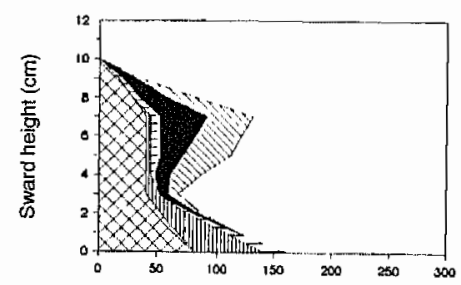

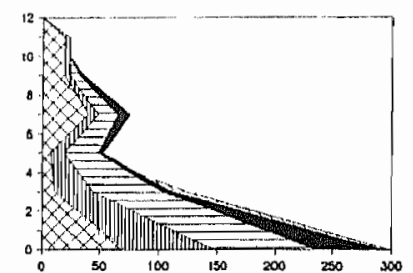

No of hits

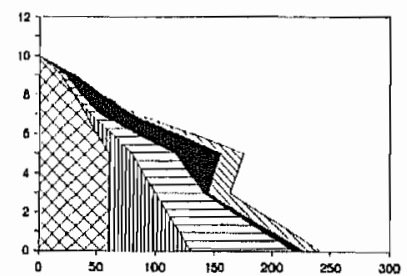

No of hits

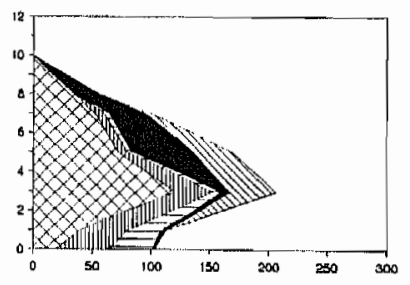

No of hits

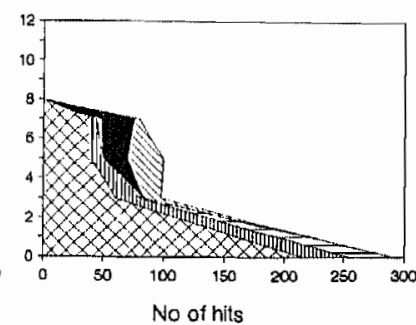

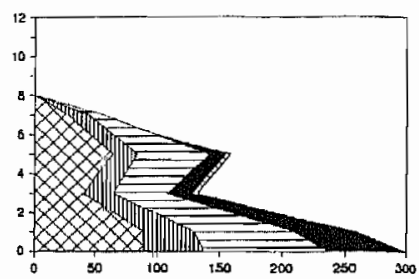
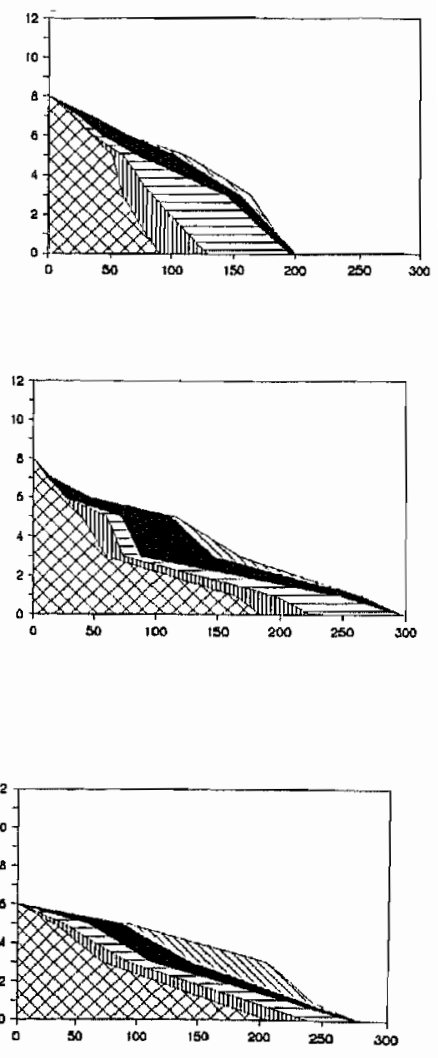

Figure 1. The vertical distribution of ryegrass leaf, stem (pseudostem + flower-stem) and dead, plus clover lamina-petiole and dead components in the swards grazed by goals at $10-8 \mathrm{~cm}$ (high), $7-5 \mathrm{~cm}$ (medium) and $5-3 \mathrm{~cm}$ (low) sward height treatments as measured by pointquadrat at each sampling date. Data are expressed as number of hits per 100 loci in each $1 \mathrm{~cm}$ of the whole sward for twenty-five points per paddock ( $囚$ ryegrass leaf; $[$ III ryegrass stem; $⿴ 囗 ⿱ 一 一)$ dead ryegrass; dead clover; white clover lamina-petiole)

0.14 , low (s.e.d. 0.012)]; dead clover [0.02, high; 0.03 , medium; and 0.01 , low (s.e.d. 0.009) and 0.03, high; 0.01, medium; and 0.01, low (s.e.d. 0.011)]. However, on the low height treatment there was a significantly lower proportion of clover flower present in the whole sward $(0.06$, high; 0.05 , medium; 0.01, low; s.e.d. $0.007, P<0.001$ ) when compared with that present at the sward surface. This was also the case for ryegrass flower-stem material $(0.11$, high; 0.10 , medium; 0.04, low; s.e.d. 
Table 2. Effect of sward height treatment on the proportion of elover laminapetiole in the whole sivard and at the sward surface and on the sward surface/whole sward ratio

\begin{tabular}{|c|c|c|c|c|c|c|}
\hline & \multicolumn{4}{|c|}{ Sward height treatment } & \multirow[b]{2}{*}{ s.e.d. } & \multirow[b]{2}{*}{ Significance } \\
\hline & Period & $10-8 \mathrm{~cm}$ & $7-5 \mathrm{~cm}$ & $5-3 \mathrm{~cm}$ & & \\
\hline \multirow[t]{4}{*}{ Whole swatd } & do & 0.09 & 0.11 & 0.10 & 0.018 & NS \\
\hline & $\mathrm{d} 33$ & 0.08 & 0.12 & $0 \cdot 12$ & $0+022$ & NS \\
\hline & $\mathrm{d} 54$ & 0.13 & 0.17 & 0.20 & 0.020 & NS \\
\hline & $\mathrm{d} 89$ & 0.13 & 0.09 & 0.13 & 0.027 & NS \\
\hline \multirow[t]{4}{*}{ Sward surface } & do & 0.12 & 0.16 & 0.12 & 0.021 & NS \\
\hline & $\mathrm{d} 33$ & 0.20 & 0.24 & $0 \cdot 20$ & 0.029 & NS \\
\hline & $\mathrm{d} 54$ & $0 \cdot 25$ & 0.30 & $0 \cdot 31$ & 0.033 & $*$ \\
\hline & $\mathrm{d} 89$ & $0 \cdot 15$ & $0 \cdot 15$ & 0.23 & 0.027 & $* *$ \\
\hline \multirow{4}{*}{$\begin{array}{l}\text { Sward surface/whole } \\
\text { sward/ratio }\end{array}$} & $\mathrm{d} 0$ & $1 \cdot 33$ & $! 45$ & 1.20 & 0.053 & NS \\
\hline & d 33 & $2 \cdot 50$ & 2.00 & $i .67$ & 0.048 & $*$ \\
\hline & $\mathrm{d} 54$ & 1.92 & 1.76 & 1.55 & 0.073 & NS \\
\hline & d89 & $1 \cdot 15$ & 1.67 & 1.77 & 0.068 & $*$ \\
\hline
\end{tabular}

NS, not significant; $* P<0.05 ; * * P<0.01$.

$0.020, P<0.05$ ), although this difference disappeared by the d54 sampling date. Throughout the experiment, live perennial ryegrass (leaf plus pseudostem plus flower-stem) was the dominant proportion in all of the sward height treatments with its leaf component making the highest contribution.

Although the leaf proportion increased from the first sampling date, that increase was higher in the whole sward than on the sward surface, decreasing from ratios of $2.48,2.29$ and 1.94 (s.e.d. 0.083 ) at d0 to ratios of $1.33,1.30$ and 1.08 ratios (s.e.d. 0.094 ) at $\mathrm{d} 89$ in the high, medium and low height treatments respectively. In contrast to leaf material, pseudostem and flower-stem proportions were present in lower proportions within the swards (always below 0.10 ), with ratios of $0.44,0.53$ and 0.56 (s.e.d. 0.0058 ) in the high, medium and low treatments, respectively, at $\mathrm{d} 0$ and decreased as the experiment progressed, particularly in the top layers of the sward, to reach values of $0.21,0.17$ and 0.40 for the ratios (s.e.d. 0.0049 ) in the high, medium and low treatments, respectively, at $\mathrm{d} 89$. By the end of the experiment, there were no significant differences between sward height treatments in the proportion of ryegrass stem across the whole sward, although there were lower leaf $(0.53$ vs. 0.65 and 0.73 ; s.e.d. $0.047, P<0.05)$ and higher pseudostem $(0.04$ vs. 0.01 and 0.01 , s.e.d. $0.019, P<0.05)$ proportions at the sward surface in the low height treatment compared with the high and medium height treatments respectively.

The proportion of live white clover increased after the treatments were imposed and reached maximum values by $\mathrm{d} 54$, either in the whole sward $(P<0.05)$ or on the sward surface $(P<0.001)$. As seen in Table 2, the average proportion of clover lamina and petiole during the experiment was higher in the sward surface layer than in the whole sward $(P<0.001)$, although by $\mathrm{d} 89$ the ratio in the high height treatment diminished to $1 \cdot 15$.

In contrast to the clover lamina-petiole ratios, dead matter ratios were below $1 \cdot 0$, indicating that the proportion of total dead matter on the sward surface was less than in the whole sward. Average ratios were $0.58,0.46$ and 0.68 ratios in the high, medium and low height treatments respectively (s.e.d. 0.052), although the high and low height treatment ratios increased to 0.75 and 1.13 , respectively, by the end of the experiment. Similarly, dead ryegrass material decreased from the beginning of the experiment $(P<0.001)$ and resulted, by the end of the experiment, in higher proportions in the whole sward $(0.13$ vs. 0.05 and 0.07 ; s.e.d. $0.036 ; P<0.05)$ and on the sward surface $(0.17$ vs. 0.07 and 0.04 ; s.e.d. 0.015 , $P<0.001)$ in those paddocks grazed at the low height compared with those at the high and medium height treatments respectively. In comparison with dead ryegrass, the proportion of dead clover by the end of the experiment reached higher values than those for dead ryegrass at the high and medium height treatments but not for the low height treatment, either in the whole sward $(0.15$ and 0.09 vs. 0.03 ; s.e.d. 0.012 , $P<0.001)$ or on the sward surface $(0.08$ and 0.05 vs. 0.01 ; s.e.d. $0.011, P<0.01$ )

\section{Animal production}

Treatment means for LW and body condition changes are given in Table 3 .

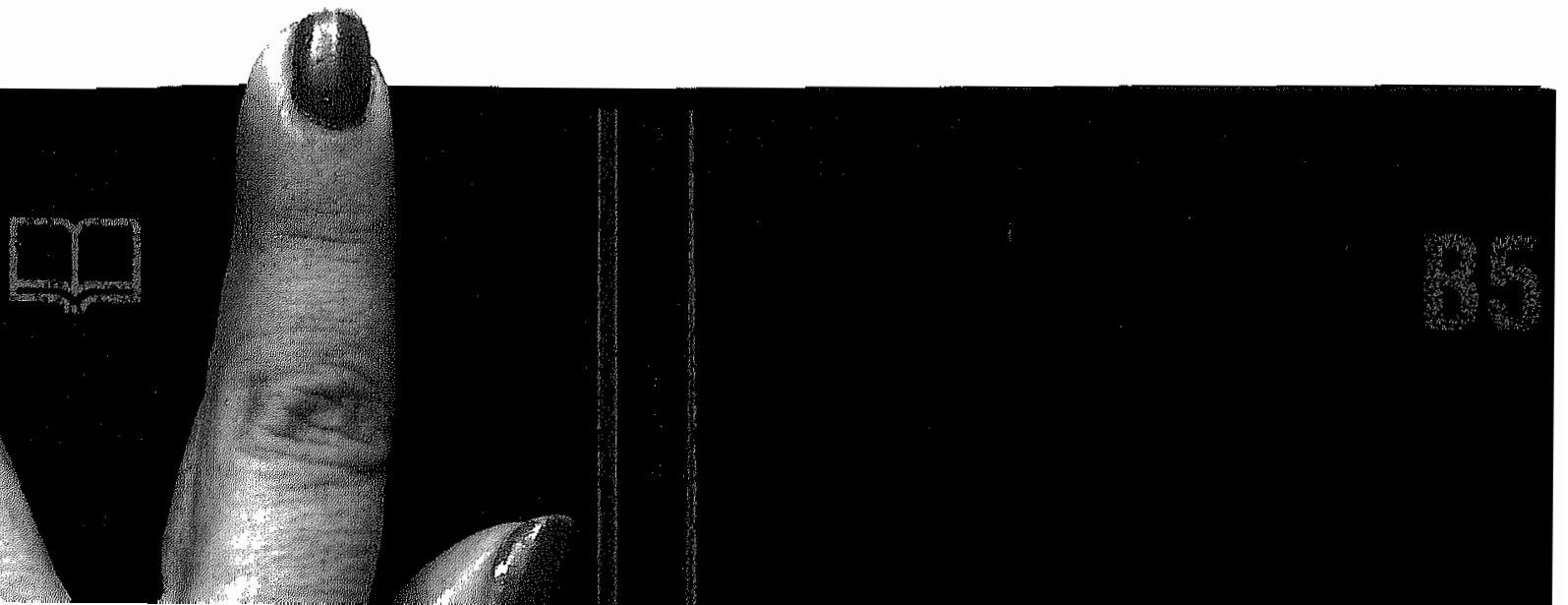


Table 3. Eiftect of sward surfice height treatment on goat liveweight change and body condition score (means, pooled s.e.d. and $P$-values)

\begin{tabular}{|c|c|c|c|c|c|}
\hline & \multicolumn{3}{|c|}{ Sward height treatment } & \multirow[b]{2}{*}{ s.e.d. } & \multirow[b]{2}{*}{$P$} \\
\hline & $10-8 \mathrm{~cm}$ & $7-5 \mathrm{~cm}$ & $5 \cdots 3 \mathrm{~cm}$ & & \\
\hline \multicolumn{6}{|l|}{ Live weight $(\mathrm{kg})$} \\
\hline do & 29.5 & $30 \cdot 7$ & $29 \cdot 8$ & 0.48 & NS \\
\hline $\mathrm{d} 33$ & $30 \cdot 8$ & $30 \cdot 7$ & 28.5 & 0.51 & $*$ \\
\hline d54 & $33 \cdot 1$ & 30.9 & $27 \cdot 7$ & 0.50 & * \\
\hline d 89 & 34.0 & $30 \nmid 4$ & 26.0 & 0.47 & $* * *$ \\
\hline Liveweight eltange ( $\mathrm{g} \mathrm{d}^{-1}$ ) & $50 \cdot 24$ & -0.01 & $-42 \cdot 30$ & 13.213 & $* * *$ \\
\hline \multicolumn{6}{|l|}{ Condition seore (units) } \\
\hline do & 225 & $2 \cdot 20$ & 2.28 & 0.051 & NS \\
\hline $\mathrm{d} 33$ & 2.61 & $2 \cdot 42$ & $2 \cdot 12$ & 0.047 & * \\
\hline d54 & 2.91 & $2 \cdot 40$ & $2 \cdot 10$ & 0.045 & $* *$ \\
\hline d89 & 3.05 & 2.29 & 1.92 & 0.060 & ***: \\
\hline Condition score change (units $d^{-1}$ ) & 0.009 & 0.001 & -0.004 & $0 \cdot 0011$ & **** \\
\hline
\end{tabular}

NS, not significant: *P<0.05; **P<0.01; ***P<0.001

Over the 89 days of the experiment, goats gained $4.50 \mathrm{~kg} \mathrm{LW}$ head $^{-1}$ on the high height treatment, whereas they lost $0.27 \mathrm{~kg} \mathrm{LW} \mathrm{head}{ }^{-1}$ on the medium height treatment and lost $3.76 \mathrm{~kg} \mathrm{LW}$ head $^{-1}$ on the low height treatment. This was accompanied with body condition gains of 0.80 and 0.07 units head ${ }^{-1}$ on the high and medium height treatments, respectively, and with a body condition loss of 0.36 units on the low height treatment (s.e.d. $0.079, P<0.001)$. During the interval d54-d89, goats had higher liveweight losses on the medium and low height treatments $(-11.6$ and $-51.3 \mathrm{~g} \mathrm{LW}$ $\mathrm{d}^{-1}$ respectively; s,e.d. 0.38 ) than for the remainder of the grazing period $\left(3.1\right.$ and $-38.2 \mathrm{~g} \mathrm{LW} \mathrm{d}^{-1}$ respectively; s.e.d. 0.42 ), whereas the liveweight pattern on goats grazing at the high height treatment showed significant wide fluctuations during the whole experimental period $(39.4,109.5$ and $25.7 \mathrm{~g}$ LW $\mathrm{d}^{-1}$ in the $\mathrm{d} 0-\mathrm{d} 33, \mathrm{~d} 33-\mathrm{d} 54$ and $\mathrm{d} 54-\mathrm{d} 89$ intervals respectively).

The liveweight gains of goats were negatively correlated with changes in clover lamina-petiole ratios $\left(R^{2}=0.544, P<0.05\right)$ but not with changes in dead matter ratios $\left(R^{2}=0.033\right.$, NS). The multiple linear regression of liveweight gain $\left(y, \mathrm{~g} \mathrm{LW} \mathrm{d}^{-1}\right)$ with the mean sward height $(P<0.001)$ between sampling dates $\left(X_{1} \mathrm{~cm}\right)$ and the change in the ratio of the vertical distribution of the clover laminapetiole component in the sward $(P<0.01)$ between sampling dates $\left(X_{2}\right)$ was significant $\left(R^{2}=0.858\right.$, $P<0.001)$ and gave the following equation:

$y=-120.4( \pm 14.10)+19.4( \pm 2.04) \chi_{1}-23.3( \pm 6.93) x_{2}$

\section{Discussion}

\section{Sward characteristics}

Patch grazing, a characteristic of cattle (Gibb and Ridout, 1986; 1988) and sheep (Clark et al., 1984) behaviour, was absent in the present trial. In their paper, Gibb and Ridout (1988) showed that analysis and interpretation based on the mean sward height may be imprecise, as swards grazed by steers typically become heterogeneous in height, showing a double normal height distribution that represented 'frequently' and 'infrequently' grazed areas. However, in the current experiment the defoliation by goats produced a high degree of sward height uniformity in the vegetation canopy in all of the treatment paddocks and consequently there was a low proportion of lightly grazed areas recorded over the whole experimental period. Several papers (Hughes et al., 1984; McCall and Lambert, 1987; Nicol and Collins, 1990; Gong et al., 1993; Betteridge el al., 1994) report that goats seem to defoliate pastures from the top downwards in successive layers and hardly penetrate into the basal horizon. Such grazing behaviour would be in accordance with a report of goat's predisposition to browse taller patches of the sward as found by D. A. Clark, J. Hodgson, A. Illios, T. Hughes, E. Robertson and D. Elston (unpublished) and cited by Mllius and Gordon (1993). Evidence in this experiment for goat browsing activity being concentrated in the upper layers of the sward came from the decreased proportion of dead and ryegrass flower-stem that occurred in the upper layers of the sward. 
There was a continued increase in the proportion of white clover lamina-petiole at the sward surface from $\mathrm{d} 0$ to $\mathrm{d} 54$. As can be seen from the weather data, reasonable clover growth was still possible and the goats' non-preference for white clover probably enhanced it. Woledge et al. (1989) showed that clover at warm temperatures has a more active growth rate and is able to maintain a position high in the canopy compared with grass; clover predominance in the sward at this particular time might aiso have been favoured by its apparent nonconsumption by goats. However, it could be that goats, as surface feeders, selected the tallest material first ( $d 0-d 33)$, exposing more growing clover at the surface that subsequently $(\mathrm{d} 33-\mathrm{d} 54)$ was more grazed relative to the whole sward. Finally, the live clover proportion declined for all sward height treatments at the sward surface in the d54-d89 interval, probably as a result of the combination of reduced growth, senescence and defoliation. Therefore, whereas grass and white clover might establish a particular balance under different height managements, it is clear that this balance is dynamic within the experimental grazing season and could be influenced by goat grazing.

Furthermore, despite a wide range of sward heights in this study, there was no consistent effect of sward height on the proportion of live white clover in the sward, unlike that reported for sheep grazing (Orr et al., 1990; Barthram et al., 1992). The proportion of ryegrass material increased steadily from the top to the bottom of the sward profiles (Figure 1), whereas, conversely, the clover proportion was higher within the upper stratum than in the lower stratum. Sward height would only affect readily prehensible material to a limited extent in swards with high white clover contents. Thus, the $5-3 \mathrm{~cm}$ (low) height treatment had higher white clover proportions in the sward surface by the end of the experiment than the $10-8 \mathrm{~cm}$ (high) and $7-5 \mathrm{~cm}$ (medium) height treatments, probably as a result of reduced competition from ryegrass at low temperatures.

Because of non-preferential defoliation of clover in the whole sward, dead clover proportions progressively rose in all the sward height treatments; this was greatest on the high height treatment, and greater in the whole sward than in the surface. However, the reverse was the case for the appearance of dead ryegrass. Its proportional cover was greater in the base of the sward probably because of an interaction of low preference and inaccessibility, as previously reported for goats by Hughes et al.
(1984) and Casey et al. (1993). Goats kept the proportion of ryegrass in the sward in a vegetative state avoiding the build-up of seed heads and dead material, with the proportion of ryegrass stems (flowerstem plus pseudostem) and white clover flowers declining from the beginning of the experiment. The great capability of goats to control reproductive swards has also been reported by Clark et al. (1984), Clark and Lambert (1989), Domingue et al. (1991) and Gurung et al. (1994). Under similar local conditions, previous work by Martinez and Osoro (1995) has reported slow pasture growth rates in autumn at a time when decomposition is occurring after dry summer periods. Therefore, much of the seedhead growth and dead herbage, if not eaten by livestock, could subsequently die and decompose, thus inhibiting live ryegrass and white clover growth. However, the goats' laxer grazing in this experiment, i.e. the $10-8 \mathrm{~cm}$ (high) sward height treatment, seemed to minimize the impact of seasonal senescence on subsequent pasture performance. This suggests that goats could be managed on these swards in late season for cleaning up the most lignified and reproductive components.

It is not easy to explain more accurately botanical differences within the experimental sward without knowing more about the goat grazing process as it is possible that this affects pasture growth and decay. Further progress will require a detailed understanding of diet selection as well as pasture changes induced by goat grazing behaviour.

\section{Animal production}

In general, goat performance was reduced as the sward height decreased. Merchant and Riach (1994) recommended that lactating cashmere goats be maintained on swards at least at a sward height of $6 \mathrm{~cm}$ to obtain satisfactory levels of performance. Radcliffe et al. (1991) showed that rotational grazing increased the post-weaning performance of does when residual sward height increased from $5-8 \mathrm{~cm}$ to $6-11 \mathrm{~cm}$. Collins and Nicol (1986) found that the intake rate of goats on a per kilogram liveweight basis fell rapidly when the herbage allowance ( $\mathrm{kg} \mathrm{DM} \mathrm{ha-1} \mathrm{d}^{-i}$ ) of a progressively defoliated sward was reduced. Therefore, the liveweight losses recorded in the current study under the lower sward height treatments may be considered normal for dry animals at the end of the grazing season.

However, although sward height had a dominant effect on goat performance, the spatial distribution 
of white clover within the canopy also had a statistically signilicant effect. Liveweight gains were lower as the proportion of the dover lamina-petiole increased on the sward surface compared with that of the whole sward. Reports from more moist enviromments (Stevens ef al., 1993) have shown, in mixed swards of ryegrass with clover, that maximum benetits on goat liveweight performance occur when $40 \%$ of the sward contained clover and herbs. However. Stevens e' al. (1992a) reported liveweight gains of only $41 \%$ compared with those achieved during spring for goats grazing prairie grass-white clover pastures. Furthermore, Stevens et al. (1992b) showed that angora-type goats reduced their liveweight gains when the proportion of white clover in the grazed stratum was greater than the red clover proportion. Thus, although a substantial presence of clover laminate on the sward surface secms to promote the intake of clover by sheep (Milne et al., 1982) it might not necessarily occur in goats. Parsons et al. (1994) suggested that the energetic cost of foraging increases substantially as the horizontal or vertical availability of the desired plant species decretses. Therefore, the cost associated with selection by goats against the horizontal layer of live white clover near to the canopy surface might have been quite important and affected their liveweight gain.

However, it could be argued that higher goat performance was linked with high white clover intakes, as liveweight gains were higher when surface clover content relative to the whole sward was lower. In addition, it can be argued that the clover fraction was not significant as liveweight loss occurred when the allowance of ryegrass leat in the sward was predominant. Therefore, the conclusions about the influence of the ratios of live clover on goat performance is less clear in this experiment than the relationships estimated between sward height and liveweight change. Complementary studies on diet selection, grazing location and intensity of utilization need to be performed to achieve a better understanding of the effect of sward clover composition on goat performance.

\section{Implications}

Because goats in this experiment seemed to be sensitive to decreasing sward height below $7-6 \mathrm{~cm}$, it would be advisable not to stock them at lower sward heights on grass/clover swards in the autumn. The integration with other species of livestock, such as sheep, into these ryegrass/white clover swards may be necessary to control increased white clover growth for the optimal management of goats.

\section{Conclusions}

Across all sward height treatments, goat grazing increased the proportion of ryegrass leaf and decreased the proportion of stem and dead matter in the whole sward and produced higher proportions of live clover on the sward surface than in the whole swarc. Liveweight performance was higher in those swards that decreased in height from $10 \mathrm{~cm}$ to $8 \mathrm{~cm}$ than from $7 \mathrm{~cm}$ to $5 \mathrm{~cm}$ and from $5 \mathrm{~cm}$ to $3 \mathrm{~cm}$ in which they lost liveweight. As senescence rates were contained and the decline in the sward of live clover was deferred, it seems that autumn swards may be able to be managed witl goats at taller heights than $7-5 \mathrm{~cm}$. However, goats responded negatively to increasing clover content, in particular at the sward surface and, to achieve satisfactory individual animal performance for mating purposes, integration with other livestock species such as sheep, seems to be necessary. Therefore, the possible grazing advantages of the use of other species with goats during the late part of the season might represent a multispecies solution to the management of grass/clover swards.

\section{Acknowledgments}

The authors wish to thank. Dr R. Celaya for assistance with the botanical analysis of the swards and Mrs Esther López for preparation of the tables. Dr M. del Pozo was funded by the Ministerio de Educación y Cultura of Spain.

\section{References}

BARTHRAM G.T. (1986) Experimental techniques: the HFRO sward stick. In Hill Farming Research Organisation Biennial Report 1984-85. pp, 29-30.

BarTHRAM G.T, and GRANT S.A. (1994) The effects of managetnent and plant variety on the composition, vertical structure and stock-carrying capacity of Lolium perenne/Trifolium repens pastures. Grass and Forage Science, 49, 360-368.

Barthram G.T., GranT S.A. and Elston D.A. (1992) The effects of sward height and nitrogen fertilizer application on changes in sward composition, white clover growth and the siock carrying capacity of an upland perennial ryegrass/white clover sward grazed by sheep for four years. Grass and Forage Science, 47 326-341.

BetTeridge K, Fletcher R.H., LiU Y., Costall D.A. and Devantier B.P. (1994) Rate of removal of grass from mixed pastures by cattle, sheep and goat grazing. Proceedings of the New Zealand Grassiand Association, 56, 61-65.

CASEY M.J., Lucas R.J. and Stevens D.R. (1993) Vertical distribution of botanical components in four pastures mixtures grazed solely by goats. Proceedings of the XVII International 
Grassland Congress. Palmerston Norh, New Zealand. pp. $882-883$.

ClARK D.A. and LAMBERT M.G. (1989) The role of goats in New Zealand hill country farming. Proceedings of the XV L hernational Grassiand Congress. Nice, France. pp. 1359-1.360.

Clark D.A., Rolston M.P., Lambert M.G. and Budding P.J. (1984) Pasture composition under mixed sheep and goat grazing on hill country. Proceedings of the New Zealand Grasslands Association, 45, 160-166.

Collins H.A. and NiCOL A.M. (1986) The consequence for feed dry matter intake of grazing sheep, cattle and goats to the sume residual herbage mass. Proceedings of the New Zealand Society of Animal Production, 46, 125-128.

DEL POzo M. and Wright I.A. (1995) Integration of sheep and goats in grazing systems on grass/clover swards. In: Laker J.P. and Russel A.J.F (eds) The Nutrition and Grazing Ecology of Speciality Fibre Producing Animals. Occasional Publication no. 3, European Fine Fibre Network. Villaviciosa, Spain. pp. $151-162$

DEMMENT M.W. and LACA E.A. (1993) The grazing ruminant: models and experimental techniques to relate sward structure and intake. In: Proceedings of the VIIth World Conference on Animal Production. Edmonton, Canada. pp. 439-460.

Domingue B.M.F., Dellow D.W. and BARry T.N. (1991) The efficiency of chewing during eating and ruminating in goats and sheep, British Ioumal of Nutrition, 65,355-363.

FORBES T.D.A. (1982) Ingestive Behaviour and Diet Selection in Grazing Catlle and Sheep. PhD thesis. University of Edinburgh. UK.

GiBB M.J. and RiDouT M.S. (1986) The fitting of frequency distributions to height measurements on grazed swards. Grass and Forage Science, 41, 247-249.

GIBB M.J. and RidouT M.S. (1988) Application of double normal frequency distributions fitted to measurements of sward height. Grass and Forage Science, 43, 131-136.

GumP H.A. (1995) Meat goat production and marketing. Jollmal of Aninal Science, 73, 291-295.

Gong Y., Hodoson J., LAMberT M.G., Chu A.C.P. and Gondon I.L. (1993) Comparison of bite weight and bite dimensions of sheep and goats grazing a range of grasses and clovers. Proceedings of the XVII Intemational Grassiand Congress. Palmerston North, New Zealand. pp. 726-728

GRANT S.A. (1993) Resource description: vegetation and sward components. In: Davies A., Baker R.D., Grant S. and Laidlaw A.S. (eds) Sward Measurentent Handbook, 2nd edn. Reading: British Grassland Society. pp. 69-98

Gurung N.K., Jallow O.A., McGregor B.A., Watson M.J., MCILroY B.K.M.H. and Holmes J.H.G. (1994) Complementary selection and intake of annual pastures by sheep and goats. Simall Ruminamt Research, 14, 185-192.

HUGHes T.P., Sykes A.R and POPPI D.P. (1984) Diet selection of young ruminants in late spring. Proceedings of the New Zealand Society of Animal Production, 44, 109-112.

ILLUUS A.W and Gordon IJ. (1993) Diet selection in mammalian herbivores, constraints and tactics. In: Hughes R.N. (ed.) Die Selection. An Interdisciplinay Approach to Foraging Behaviour. Oxford: Blackwell Scientific Publications. pp. 157-181.

Lambers M.G., Clark D.A., BetTeridge K. (1987) Grazing behaviour of goats on weed infested hill pastures in New Zealand. Proceedings of the $N$ International Conference on Goats, Brazillia, 2, 1307

Lawes Agricultural Trust (1990) Genstat 5. Reference Mantual. Oxford: Oxford University Press.
MCCALL D.G. and LAMHERT M.C. (1987) Pasture feeding of goats. In: Nicol A.M. (ed.) Livestork Feeding on Pasture. New Zealcone Society of Animal Production. Decusional Publication, 10. $105-109$

MCGikecok B.A. (1985) Complementary grazing of gous and sheep in the temperate zone. Procedings of the First Intemational Cashmere Seminas: Australian University. Camberra. pp. $103-123$.

Maktínez A. and Osoro K. (1995) Respuesta del ganado ovino a la altura de la hierba disponible en pastos de raigrás y trébol. Información Técnica Económica Agraria, 16, 171-173.

MERCHANT M. and RIACH D.J. (1994) 'The intake and performance of cashmere goats grazing sown swards. Grass and Forage Science, 49, 429-437.

Mitse J.A., HoDgson J., Thompson R., SOUTER W.G. and BARTHRAM G.T. (1982) The diet ingested by sheep grazing swards differing in white clover and perennial ryegrass content Grass and Forage Science, 37, 204-218.

Nicol A.M. and CoLlins H.A. (1990) Estimation of the pasture horizons grazed by cattle, sheep and goats during single and mixed grazing. Proceedings of the New Zealand Society of Animal Production, 50, 49-53.

Ork R.J., Parsons A.J., Penning P.D. and Treacher T.T. (1990) Sward composition, animal performance and the potential production of grass/white ciover swards continuously stocked with sheep. Grass and Forage Science, 45, 325-336.

Osoro K. and MARTínez A. (1995) Grazing behaviour and performance of goats and sheep on natural and improved vegetation. In: Laker J.P. and Russel A.J.F. (eds) The Nutrition and Grazing Ecology of Speciality Fibre Producing Animals. Occasional Publication no. 3, European Fine Fibre Network Villaviciosa, Sptin. pp. 109-126.

Parsons A.J., Thornley J.H.M., Newman J.A. and Penning P.D (1994) A mechanistic model of sone physical deterninants of intake rate and diet selection in two-species temperate grassland sward. Functional Ecology, 8, 187-204.

RADCLIFFE J.E. and FRANCIS S.M. (1988) Goat farming practises on high producing pastures. Proceedings of the New Zealand Grassland Association, 48, 199-205.

RADCLIFFE J.E. TOWNSEND R.J. and BaIRo D.B. (1991) Mixed and separate grazing of sheep and goats at two stocking rates. New Zeuland Joumal of Agricultural Research, 34, 167-176.

Russel A.J.F. (1990) Body condition scoring of goats. Scottish Cashmere Producers Association Newsletier, 10, 3 .

STEvens D.R. BAXTER G.S. CASEY M.J. MILler K.B. and LUCAS R.J. (1992a) A comparison of six grasses for animal production. Proceedings of the New Zealand Grassland Association, 54, 147-150.

Stevens D.R., CASeY M.J., Lucas R.J., Baxter G.S, and MILLER K.B. (1992b) Angora goat production from different legumes mixed with ryegrass. Proceedings of the New Zealant of Animal Production, 52, 97-99.

Stevens D.R., Casey M.J., Baxter G.S. and Miller K.B. (1993) A response of angora-type goats to increases of legume and chicory content in mixed pastures. Proceedings of the XVII Intemational Grassland Congress, Palmerstom North. New Zealand. pp. 1300-1301

TOWNSEND R.J. and RADCLIFFE J.E. (1990) Lamb growth rates improve as goat to sheep ratio increases. Proceedings of the New Zealand Grassland Association, 52, 115-118.

WOLEDGE J., DAVIDSON I.A and TEwson V. (1989) Photosynthesis during winter in ryegrass/white clover mixtures in the field. New Phytologist, 113, 275-281.

(Received 16 December, 1996; revised 5 March, 1997)

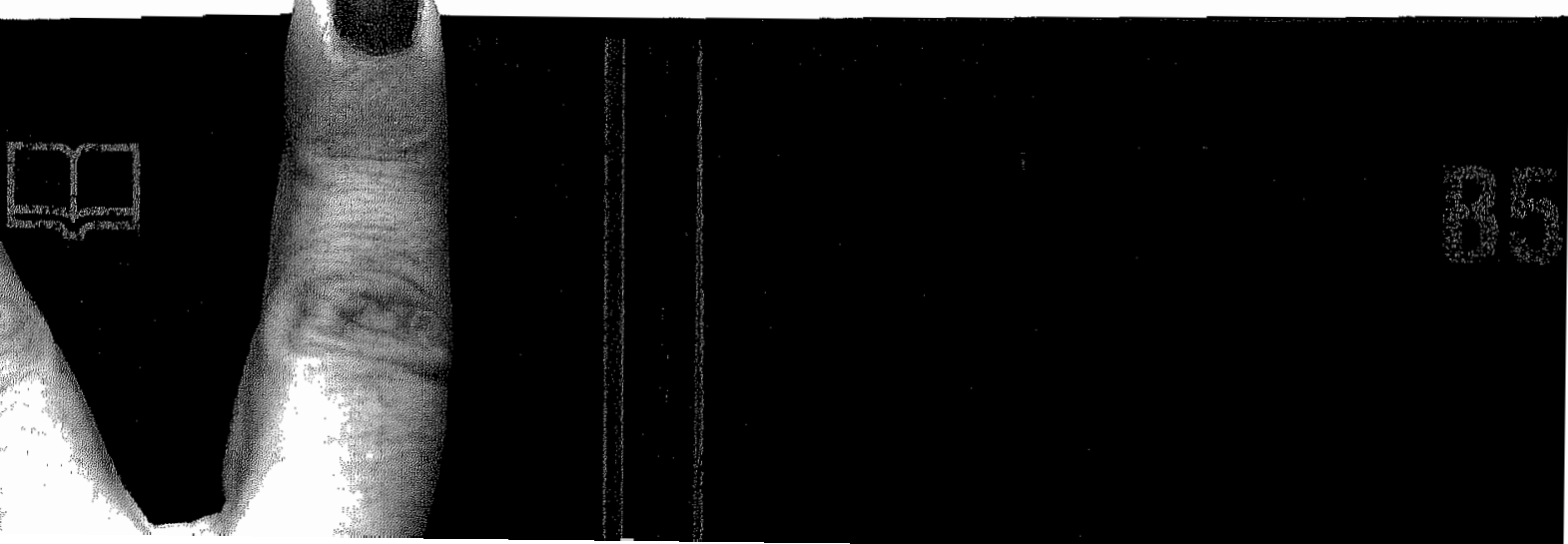

